\title{
Endogenous stem cell proliferation after central nervous system injury: alternative therapeutic options
}

\author{
Nicholas C. Bambakidis, M.D., Nicholas Theodore, M.D., Peter Nakaji, M.D., \\ Adrian Harvey, B.S., Volker K. H. Sonntag, M.D., Mark C. Preul, M.D., \\ and Robert H. Miller, Ph.D.
}

\author{
Division of Neurological Surgery, Barrow Neurological Institute, St. Joseph's Hospital and Medical \\ Center, Phoenix, Arizona; and Department of Neurosciences, Case Western Reserve University, \\ Cleveland, Ohio
}

\begin{abstract}
The continuous regeneration of glial cells arising from endogenous stem cell populations in the central nervous system (CNS) occurs throughout life in mammals. In the ongoing research to apply stem cell therapy to neurological diseases, the capacity to harness the multipotential ability of endogenous stem cell populations has become apparent. Such cell populations proliferate in response to a variety of injury states in the CNS, but in the absence of a supportive microenvironment they contribute little to any significant behavioral recovery. In the authors' laboratory and elsewhere, recent research on the regenerative potential of these stem cells in disease states such as spinal cord injury has demonstrated that the cells' proliferative potential may be greatly upregulated in response to appropriate growth signals and exogenously applied trophic factors. Further understanding of the potential of such multipotent cells and the mechanisms responsible for creating a favorable microenvironment for them may lead to additional therapeutic alternatives in the setting of neurological diseases. These therapies would require no exogenous stem cell sources and thus would avoid the ethical and moral considerations regarding their use. In this review the authors provide a brief overview of the enhancement of endogenous stem cell proliferation following neurological insult.
\end{abstract}

KEY WordS - endogenous stem cell - spinal cord injury - sonic hedgehog glycoprotein

\section{OVERVIEW}

Stem cell therapy in the setting of CNS injury has become increasingly promising. Theoretically, the pluripotential nature of these precursor cell populations allows them to develop along any neural lineage. Consequently, their progeny potentially can contribute to repair mechanisms, which may take the form of neuronal regeneration, remyelination, prevention of demyelination, or amelioration of scar formation. Embryonic stem cells also maintain a highly proliferative and migratory nature, both of which contribute to the role that they may play in the restoration of function., ${ }^{2,7}$ These cells have been driven to terminal differentiation along all glial lineages in animal models, and motor neurons have been derived in vitro from pluripotent neural progenitors. ${ }^{20,49}$

For most of the twentieth century, it was believed that stem cells existed only transiently during mammalian development. Subsequent investigation has demonstrated neural progenitor cell rests in the CNS of adult mammals. Although usually quiescent and localized, these cells

Abbreviations used in this paper: BMP = bone morphogenetic protein; $\mathrm{CNS}=$ central nervous system; $\mathrm{EGF}=$ epidermal growth factor; FGF-2 = fibroblast growth factor -2 ; Shh = sonic hedgehog; $\mathrm{TBI}=$ traumatic brain injury. remain available for replication and maturation throughout life, not just during embryonal development. ${ }^{10,14,22}$

\section{Endogenous Stem Cells in the Adult CNS}

The presence of endogenous stem cell populations in the adult mammalian CNS has led to the discovery that these cells primarily reside in discrete anatomical zones (Fig. 1). In the brain, these cells are concentrated in the hippocampus and the subventricular zone along the lateral wall of the lateral ventricle..$^{10,22}$ Some investigators also have identified neuronal cell-specific progenitors within the dentate gyrus. ${ }^{41}$ Endogenous stem cell populations have been identified around the central canal of the spinal cord; in the ependymal layer of the fourth ventricle $;^{14,43,45}$ and in the hypothalamus, ${ }^{27}$ optic nerve, ${ }^{33}$ and substantia nigra. ${ }^{21}$ In many of these locations, the exposure of these cell populations to injury in the surrounding tissue results in a proliferative response wherein most of the progenitor cells mature along an astroglial lineage. ${ }^{35}$

The signals that influence the development of neural progenitor cells along a particular lineage have been partially elucidated. Factors such as EGF, insulin-like growth factor-I, and FGF-2 have direct effects on the development of adult neural stem cells., ${ }^{2,35}$ For example, administration of FGF-2 and EGF results in a 50-fold increase in the degree 
of neurogenesis resulting from ischemic injury. ${ }^{31}$ The tissue levels of these signals are elevated substantially after spinal cord injury, and the interaction of these cytokines is critical in influencing stem cells to develop down a particular lin-

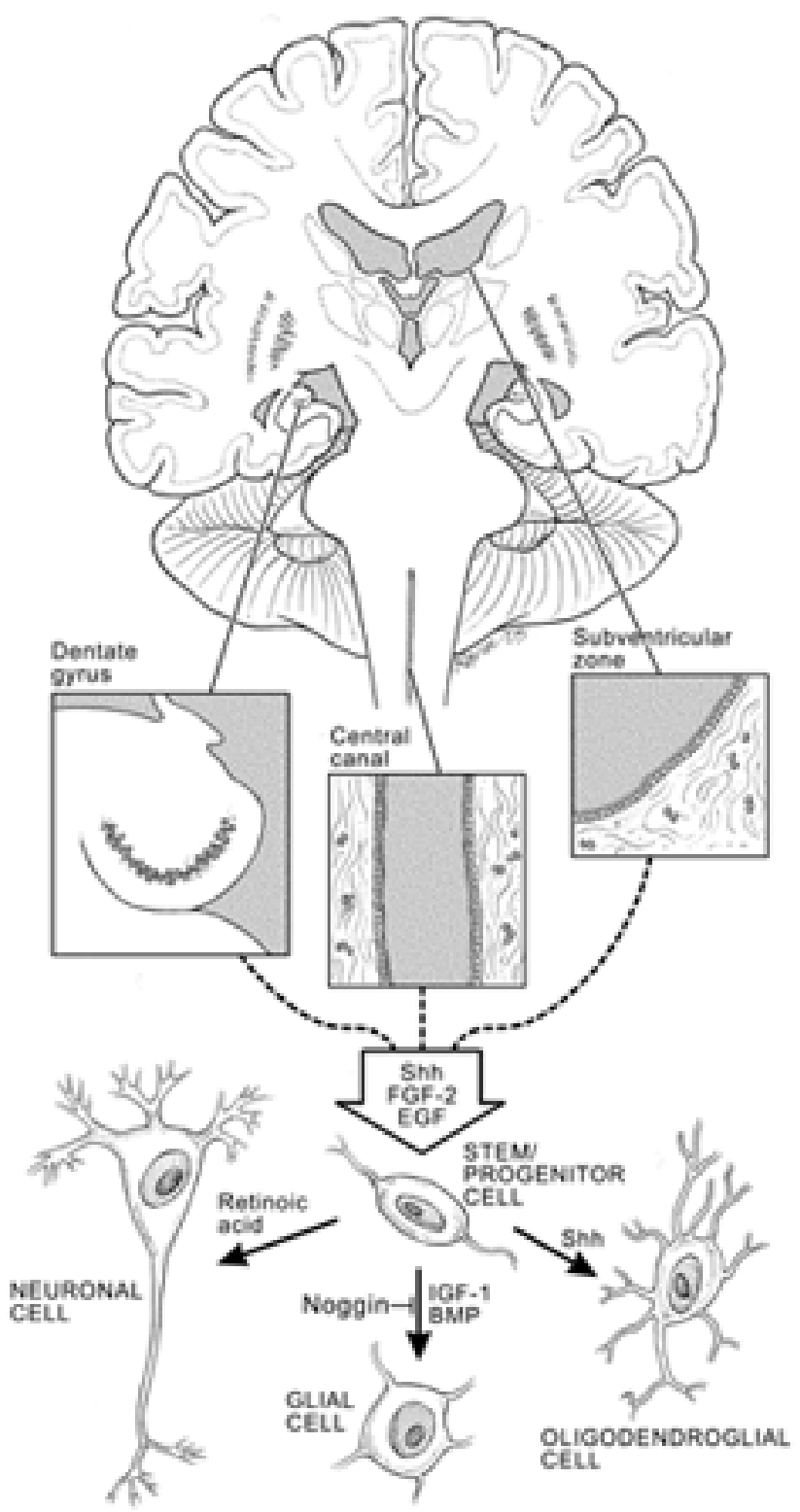

Fig. 1. Schematic illustration of endogenous stem cell rests in adult mammals and of the signals inducing proliferation and maturation along definitive glial lines. Endogenous progenitors have been identified in the hippocampal dentate gyrus, the subventricular zone, and the central canal of the spinal cord. Proliferation of primitive-appearing cells with bipolar processes can be stimulated by factors such as FGF-2 and EGF-1. These progenitors then differentiate into a particular neural form after exposure to factors such as Shh or retinoic acid. Exposure of stem cells to BMPs promotes astrocytic differentiation, whereas delivery of the BMP antagonist Noggin supports neuronal differentiation. An undifferentiated progenitor cell may therefore give rise to either astroglial, oligodendroglial, or neuronal offspring. IGF-1 = insulin-like growth factor-I. eage. ${ }^{9}$ The modification of such microenvironmental cues is critical so that the previously observed tendency of endogenous neural progenitor cells to differentiate mostly into astrocytes after injury can be altered.

\section{Sonic Hedgehog Induces Endogenous Stem Cell Proliferation}

During development, the relative concentration of a variety of small molecules has considerable influence over the particular fate of these multipotent progenitors. The BMPs play critical roles in the proliferation and maturation of progenitor cells in adults. ${ }^{23,35}$ The administration of $\mathrm{BMP}^{7}$ induces neuronal repair and provides a neuroprotective effect in ischemic rat brains. ${ }^{8}$ The administration of Shh has a crucial role in the modulation of stem cell proliferation in the hippocampus. ${ }^{18}$ A member of the hedgehog family of secreted glycoproteins, which affect the development of many cell groups and organs, Shh is expressed throughout the CNS and profoundly affects the development of the embryonic notochord. ${ }^{6,17,29,40}$ This glycoprotein mediates notochord-influenced anterior spinal cord motor neuron induction and induces the migration and proliferation of oligodendrocyte precursors. . $^{15,17,31,36}$ Constitutive expression of Shh in the developing rat brain results in bursts of stem cell proliferation in the dorsal columns of the spinal cord..$^{39}$ The administration of clonal DNA encoding Shh expression in the adult rat brain produces a threefold increase in the proliferation of endogenous stem cells that later mature into neurons. ${ }^{18}$ The removal of Shh signaling during development dramatically reduces the number of neural progenitors in the postnatal subventricular zone and hippocampus, whereas stimulation of the hedgehog pathway in the mature rodent brain by using oral Shh agonists increases the number of proliferating cells in these brain regions. ${ }^{25}$

\section{Neurological Disorders and Response of Endogenous Stem Cells to Injury}

As noted, endogenous stem cell populations respond to injury primarily through proliferation and maturation into astrocytes..$^{35}$ Much smaller numbers differentiate into oligodendrocytes and neurons. Microenvironmental cues play an important role in the development and maturation of these cells in the context of CNS injury. For example, although embryonically derived oligodendrocyte progenitors readily myelinate in the injured spinal cord after cellular transplantation, the capacity of similar endogenously derived precursors to become myelinated seems limited. This limitation is found despite a marked increase in the number of oligodendrocyte progenitors observed after spinal cord injury. ${ }^{28}$ Yamamoto, et al. ${ }^{47}$ hypothesized that the lack of neuronal differentiation after CNS injury is related to upregulation of the Notch signal pathway. The increased levels of various cytokines within the microenvironment surrounding the area of injury also may contribute a lack of trophic support for maturation into nonastrocytic lineages. ${ }^{9,16,32,46}$

Despite these obstacles, the induction and manipulation of endogenous stem cell populations have shown promise in a variety of laboratory investigations pertinent to neurological disorders and are targets of intensive investigation. Researchers continue to explore the potential for neural regeneration through endogenous stem cell manipulation in 
disorders of the basal ganglia such as Huntington and Parkinson diseases. ${ }^{13,30}$ Evidence of neurogenesis, stem cell proliferation, migration, and stem cell-mediated improvement of recovery has also been found in animal models of ischemic brain injury. ${ }^{1,4,11,26,31}$ Research has focused on the ability of stem cells to alter mechanisms of neural repair in models of traumatic injury in the CNS.

Traumatic Brain Injury. Significant work has focused on the ability of neural progenitor cells to promote functional recovery after TBI. The ability of pluripotent cells to mature into multiple cell types may be of particular benefit in the setting of trauma in which a combination of demyelination, disruption of neuronal networks, and astrocytic scar formation all contribute to injury in various degrees. The transplantation of exogenous neural progenitor cells in animal models of TBI has shown promise in promoting behavioral and motor recovery. ${ }^{24,42}$ These cells respond to signals in injured brain tissue and differentiate into neurons and glia. Other studies have shown rapid (though incomplete) motor recovery during the initial few weeks following transplantation of immortalized or stromal cell transplants after $\mathrm{TBI}^{34,38,44}$

Neural progenitor cells derived from E14.5 mouse brains and transplanted 1 week after TBI survived for 1 year and stained positively for chondroitin sulfate proteoglycan, also called NG2 (oligodendrocyte progenitor marker) but not for neuronal, astrocytic, or microglial markers..$^{42}$ These cells migrate to the site of injury and enhance motor and cognitive recovery. These findings imply that neuronal recovery is not a prerequisite for functional improvement.

The data are less clear for endogenous stem cells. Rice, et al. ${ }^{37}$ demonstrated proliferation and neuronal differentiation in rodent brains as long as 10 days postinjury, although no evidence of behavioral improvement was available. It is likely that the numbers of such cells remain too low to contribute to a significant healing response and that they are inhibited by the trophic factors released after severe trauma. The injection of exogenous progenitor cells attenuates neuronal degeneration and the proliferation of endogenous progenitor cells. ${ }^{12}$

Spinal Cord Injury. Analogous to research on exogenous stem cell transplantation in TBI, functional improvement has followed such transplantation in animal models of spinal cord injury. ${ }^{32,35}$ Similar data regarding the ability of stromal cells to support axonal growth and ameliorate demyelination have been presented. ${ }^{3}$ Direct cellular transplantation of neural stem cells that have been committed to an oligodendrocytic lineage but retain the migratory and proliferative capacity of progenitor cells results in clinically significant functional recovery and axonal conduction after injury. ${ }^{5,19}$ Investigations into the manipulation and fate of endogenous stem cell populations within the spinal cord have demonstrated that these cells proliferate in response to injury, but have provided no evidence of significant neurogenesis. ${ }^{16,22,48}$ This proliferative potential is increased by the addition of stimulating factors such as Shh. ${ }^{6}$

In models of demyelinating injury in the dorsal column of adult rats, the numbers of progenitor cells have increased in the gray and white matter of the spinal cord around the level of injury as well as around the central canal (Figs. 2 and 3). These areas of proliferation extend into the dorsal columns and stain positively for nestin (Fig. 4). In models

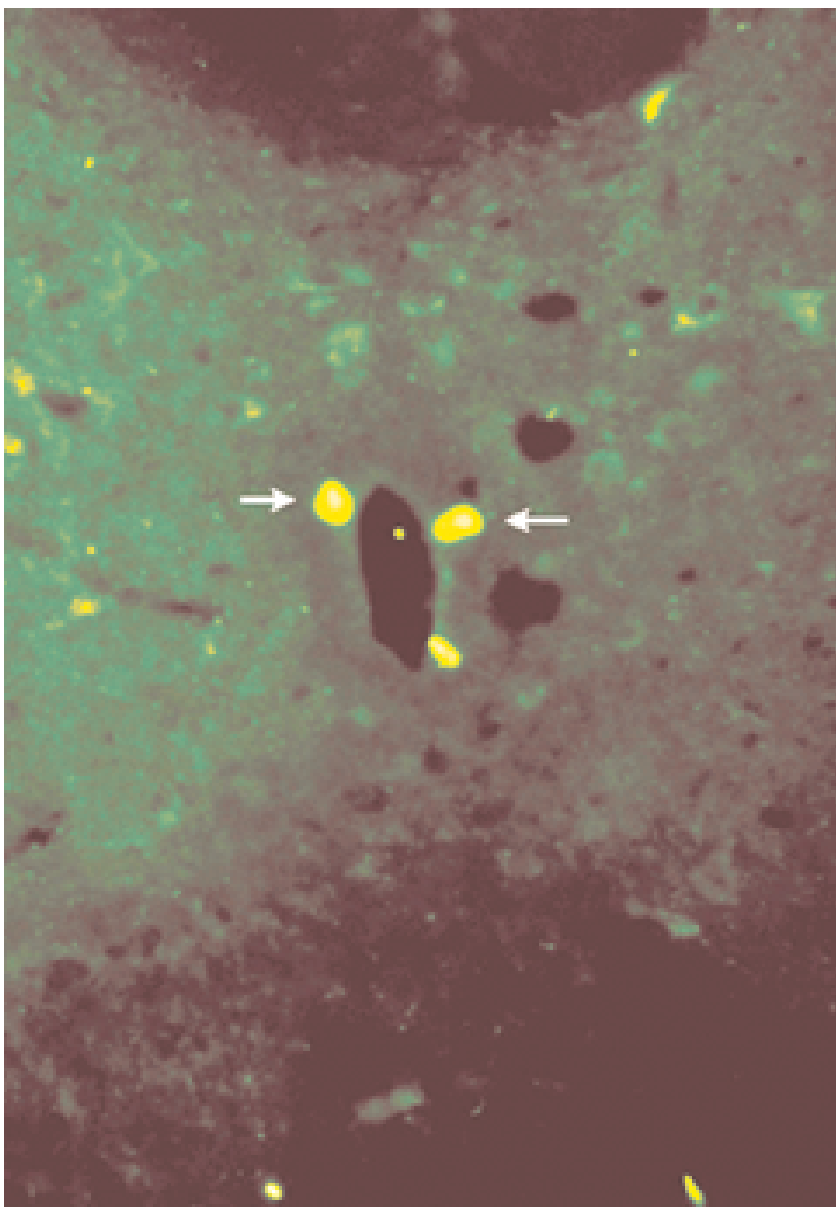

Fig. 2. Photomicrograph of bromodeoxyuridine-stained dividing cells (arrows) located around the central canal in adult rodent spinal cords after a demyelinating lesion that was exposed to recombinant Shh. These cells represent endogenous neural progenitors stimulated by the combination of demyelination and Shh. Fluorescent stain for bromodeoxyuridine, original magnification $\times 200$.

of spinal cord contusion in adult rats, the addition of Shh to the site of injury has been associated with a strong trend toward improved functional recovery and axonal conduction compared with findings in control animals. ${ }^{5}$ Likewise, the numbers of neural progenitors observed in the spinal cords of treated animals are greatly increased, both in the dorsal columns and in dissociated cell cultures incubated for 7 days (Fig. 5). Although the ultimate fate and plasticity of these progenitors have yet to be determined, the functional improvement and partial recovery observed seem to indicate that a future therapeutic role is possible.

\section{CONCLUSIONS}

The study of endogenous stem cell populations in the adult mammalian CNS continues to demonstrate potential therapeutic benefits for the treatment of neurological diseases. Further study to delineate the trophic factors contributing to a supportive microenvironment is required to 


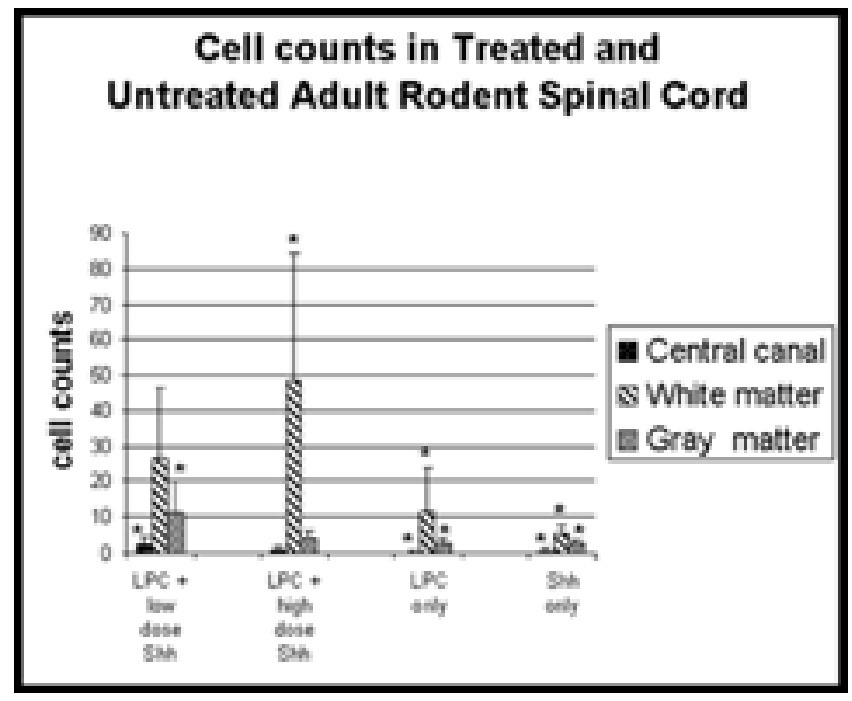

Fig. 3. Bar graph showing the increase in the numbers of actively dividing cells in spinal cord sections of adult rodents. Rats with a lesion were treated with a low dose $(3 \mu \mathrm{l})$ or a high dose $(6 \mu \mathrm{l})$ of Shh, and rodents without a lesion were given a high dose of Shh. Consistently significant increases in the number of proliferating cells followed exposure to Shh in rats with a lesion. Data were analyzed using repeated-measures analysis of variance, followed by the Student-Newman-Keuls post hoc t-test. Asterisks designate probability values of less than 0.01 . LPC $=$ lysophosphatidyl choline. (Reprinted from Bambakidis NC, Wang R-Z, Franic L, Miller RH: Sonic hedgehog-induced neural precursor proliferation after adult rodent spinal cord injury. J Neurosurg 99 (Suppl 1):70-75, 2003.)

allow cellular manipulation. Such studies would be designed to maximize the cells' contribution to a longlasting healing response. The development of systemically administered growth factors such as intravenously delivered Shh agonists and other agents will allow study of the effects of

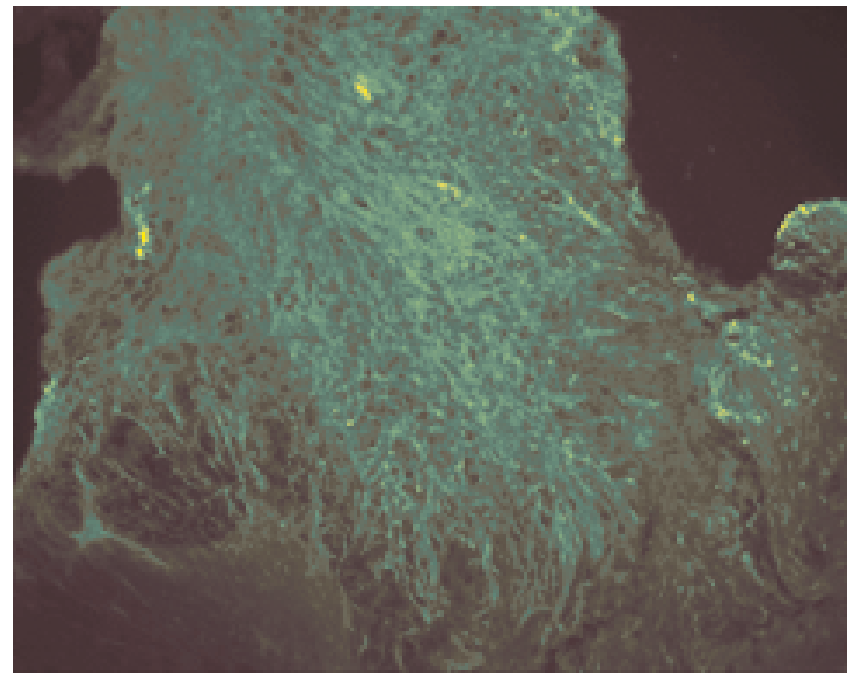

Fig. 4. Photomicrograph showing diffuse positivity for nestin in dorsal regions of hyperproliferation after administration of exogenous recombinant Shh in a rat with a demyelinating spinal cord injury. Nestin is an intermediate filament protein found in CNS precursors. Nestin staining, original magnification $\times 100$.

chronic growth factor activity within the CNS after injury without requiring direct injection of the material into the spinal cord. By manipulating microenvironments, it may be discovered that innate reparative mechanisms are adequate to restore functional abilities. Endogenous therapy potentially obviates the need to harvest exogenous stem cells. Currently, this area of study is limited by our knowledge of the delicate balance of cellular homeostasis. The more knowledge we acquire about the innate potential for regeneration, the less we may have to rely on exogenous cell lines. Further research is required to determine whether such cellular manipulation is feasible as a treatment strate-
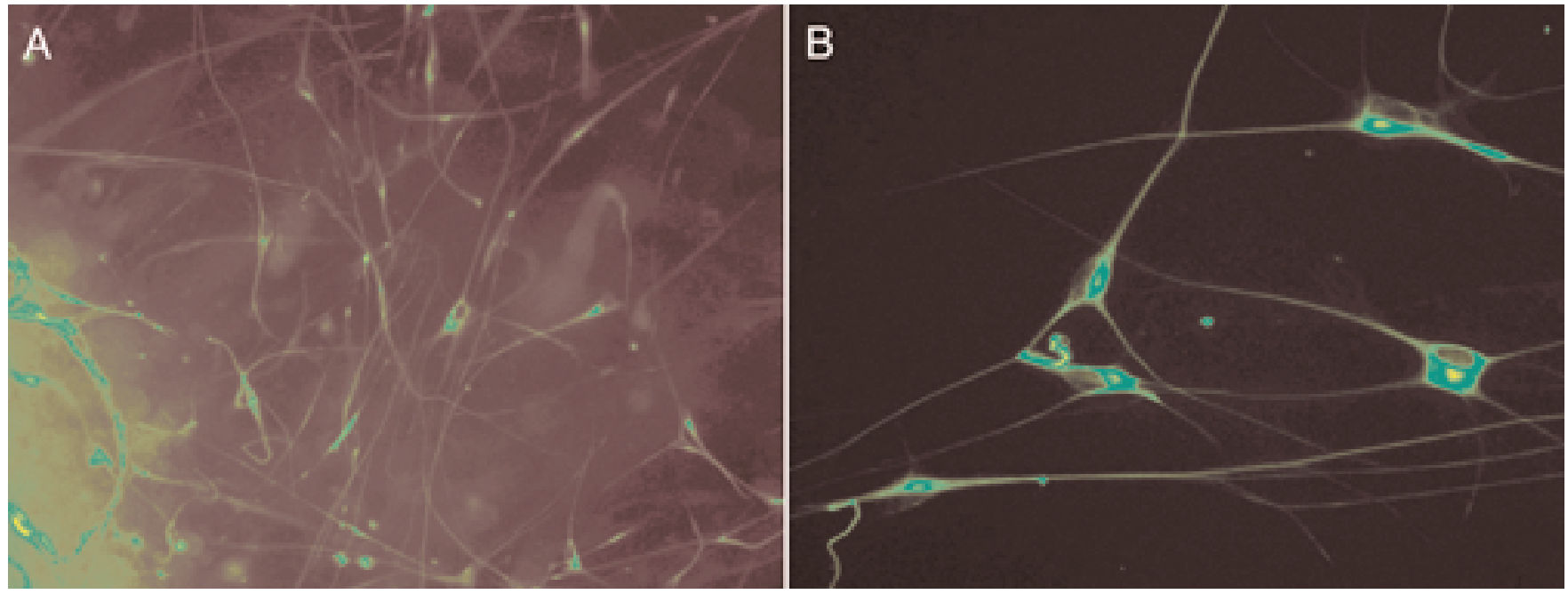

Fig. 5. Photomicrographs showing dorsal explant cultures from the spinal cords of rats after a contusive spinal cord lesion that was treated with Shh. These are low-power and high-power images of nestin-positive neural precursors. These primitive-appearing cells characteristically demonstrate a bipolar morphology and are highly motile and proliferative. Nestin staining, original magnifications $\times 50(\mathrm{~A})$ and $\times$ 200 (B). 
gy and whether it can sustain functional improvements after a severe injury to the CNS.

\section{References}

1. Abrahams JM, Gokhan S, Flamm ES, et al: De novo neurogenesis and acute stroke: are exogenous stem cells really necessary? Neurosurgery 54:150-156, 2004

2. Agrawal S, Schaffer DV: In situ stem cell therapy: novel targets, familiar challenges. Trends Biotechnol 23:78-83, 2005

3. Ankeny DP, McTigue DM, Jakeman LB: Bone marrow transplants provide tissue protection and directional guidance for axons after contusive spinal cord injury in rats. Exp Neurol 190:17-31, 2004

4. Arvidsson A, Collin T, Kirik D, et al: Neuronal replacement from endogenous precursors in the adult brain after stroke. Nat Med 8:963-970, 2002

5. Bambakidis NC, Miller RH: Transplantation of oligodendrocyte precursors and sonic hedgehog results in improved function and white matter sparing in the spinal cords of adult rats after contusion. Spine J 4:16-26, 2004

6. Bambakidis NC, Wang RZ, Franic L, et al: Sonic hedgehog-induced neural precursor proliferation after adult rodent spinal cord injury. J Neurosurg 99 (Suppl 1):70-75, 2003

7. Bottai D, Fiocco R, Gelain F, et al: Neural stem cells in the adult nervous system. J Hematother Stem Cell Res 12:655-670, 2003

8. Chang $\mathrm{CF}$, Lin $\mathrm{SZ}$, Chiang $\mathrm{YH}$, et al: Intravenous administration of bone morphogenetic protein-7 after ischemia improves motor function in stroke rats. Stroke 34:558-564, 2003

9. Frisen J, Johansson CB, Torok C, et al: Rapid, widespread, and longlasting induction of nestin contributes to the generation of glial scar tissue after CNS injury. J Cell Biol 131:453-464, 1995

10. Gage FH: Mammalian neural stem cells. Science 287:1433-1438, 2000

11. Haas S, Weidner N, Winkler J: Adult stem cell therapy in stroke. Curr Opin Neurol 18:59-64, 2005

12. Hagan M, Wennersten A, Meijer X, et al: Neuroprotection by human neural progenitor cells after experimental contusion in rats. Neurosci Lett 351:149-152, 2003

13. Hermann A, Gerlach M, Schwarz J, et al: Neurorestoration in Parkinson's disease by cell replacement and endogenous regeneration. Expert Opin Biol Ther 4:131-143, 2004

14. Horner PJ, Power AE, Kempermann G, et al: Proliferation and differentiation of progenitor cells throughout the intact adult rat spinal cord. J Neurosci 20:2218-2228, 2000

15. Jessell TM: Neuronal specification in the spinal cord: inductive signals and transcriptional codes. Nat Rev Genet 1:20-29, 2000

16. Johansson CB, Momma S, Clarke DL, et al: Identification of a neural stem cell in the adult mammalian central nervous system. Cell 96:25-34, 1999

17. Krauss S, Concordet JP, Ingham PW: A functionally conserved homolog of the Drosophila segment polarity gene hh is expressed in tissues with polarizing activity in zebrafish embryos. Cell 75:1431-1444, 1993

18. Lai K, Kaspar BK, Gage FH, et al: Sonic hedgehog regulates adult neural progenitor proliferation in vitro and in vivo. Nat Neurosci 6:21-27, 2003

19. Lee KH, Yoon do H, Park YG, et al: Effects of glial transplantation on functional recovery following acute spinal cord injury. J Neurotrauma 22:575-589, 2005

20. Li XJ, Du ZW, Zarnowska ED, et al: Specification of motoneurons from human embryonic stem cells. Nat Biotechnol 23: 215-221, 2005

21. Lie DC, Dziewczapolski G, Willhoite AR, et al: The adult substantia nigra contains progenitor cells with neurogenic potential. J Neurosci 22:6639-6649, 2002

22. Lie DC, Song H, Colamarino SA, et al: Neurogenesis in the adult brain: new strategies for central nervous system diseases. Annu Rev Pharmacol Toxicol 44:399-421, 2004

23. Lim DA, Tramontin AD, Trevejo JM, et al: Noggin antagonizes BMP signaling to create a niche for adult neurogenesis. Neuron 28:713-726, 2000

24. Lu D, Li Y, Mahmood A, et al: Neural and marrow-derived stromal cell sphere transplantation in a rat model of traumatic brain injury. J Neurosurg 97:935-940, 2002

25. Machold R, Hayashi S, Rutlin M, et al: Sonic hedgehog is required for progenitor cell maintenance in telencephalic stem cell niches. Neuron 39:937-950, 2003

26. Magavi SS, Leavitt BR, Macklis JD: Induction of neurogenesis in the neocortex of adult mice. Nature 405:951-955, 2000

27. Markakis EA, Palmer TD, Randolph-Moore L, et al: Novel neuronal phenotypes from neural progenitor cells. J Neurosci 24: 2886-2897, 2004

28. McDonald JW, Becker D, Holekamp TF, et al: Repair of the injured spinal cord and the potential of embryonic stem cell transplantation. J Neurotrauma 21:383-393, 2004

29. Miao N, Wang M, Ott JA, et al: Sonic hedgehog promotes the survival of specific CNS neuron populations and protects these cells from toxic insult In vitro. J Neurosci 17:5891-5899, 1997

30. Mohapel P, Brundin P: Harnessing endogenous stem cells to treat neurodegenerative disorders of the basal ganglia. Parkinsonism. Relat Disord 10:259-264, 2004

31. Nakatomi H, Kuriu T, Okabe S, et al: Regeneration of hippocampal pyramidal neurons after ischemic brain injury by recruitment of endogenous neural progenitors. Cell 110:429-441, 2002

32. Okano H, Ogawa Y, Nakamura M, et al: Transplantation of neural stem cells into the spinal cord after injury. Semin Cell Dev Biol 14: 191-198, 2003

33. Palmer TD, Markakis EA, Willhoite AR, et al: Fibroblast growth factor- 2 activates a latent neurogenic program in neural stem cells from diverse regions of the adult CNS. J Neurosci 19:8487-8497, 1999

34. Philips MF, Mattiasson G, Wieloch T, et al: Neuroprotective and behavioral efficacy of nerve growth factor-transfected hippocampal progenitor cell transplants after experimental traumatic brain injury. J Neurosurg 94:765-774, 2001

35. Picard-Riera N, Nait-Oumesmar B, Baron-Van Evercooren A: Endogenous adult neural stem cells: limits and potential to repair the injured central nervous system. J Neurosci Res 76: 223-231, 2004

36. Porter JA, Young KE, Beachy PA: Cholesterol modification of hedgehog signaling proteins in animal development. Science 274:255-259, 1996

37. Rice AC, Khaldi A, Harvey HB, et al: Proliferation and neuronal differentiation of mitotically active cells following traumatic brain injury. Exp Neurol 183:406-417, 2003

38. Riess P, Zhang C, Saatman KE, et al: Transplanted neural stem cells survive, differentiate, and improve neurological motor function after experimental traumatic brain injury. Neurosurgery 51:1043-1054, 2002

39. Rowitch DH, St.-Jacques B, Lee SM, et al: Sonic hedgehog regulates proliferation and inhibits differentiation of CNS precursor cells. J Neurosci 19:8954-8965, 1999

40. Ruiz I Altaba A, Palma V, Dahmane N: Hedgehog-Gli signalling and the growth of the brain. Nat Rev Neurosci 3: 24-33, 2002

41. Seaberg RM, van der Kooy D: Adult rodent neurogenic regions: the ventricular subependyma contains neural stem cells, but the dentate gyrus contains restricted progenitors. J Neurosci 22: 1784-1793, 2002

42. Shear DA, Tate MC, Archer DR, et al: Neural progenitor cell transplants promote long-term functional recovery after traumatic brain injury. Brain Res 1026:11-22, 2004

43. Shihabuddin LS, Horner PJ, Ray J, et al: Adult spinal cord stem cells generate neurons after transplantation in the adult dentate gyrus. J Neurosci 20:8727-8735, 2000 
44. Tate MC, Shear DA, Hoffman SW, et al: Fibronectin promotes survival and migration of primary neural stem cells transplanted into the traumatically injured mouse brain. Cell Transplant 11:283-295, 2002

45. Weiss S, Dunne C, Hewson J, et al: Multipotent CNS stem cells are present in the adult mammalian spinal cord and ventricular neuroaxis. J Neurosci 16:7599-7609, 1996

46. Widenfalk J, Lundstromer K, Jubran M, et al: Neurotrophic factors and receptors in the immature and adult spinal cord after mechanical injury or kainic acid. J Neurosci 21:3457-3475, 2001

47. Yamamoto S, Nagao M, Sugimori M, et al: Transcription factor expression and Notch-dependent regulation of neural progenitors in the adult rat spinal cord. J Neurosci 21:9814-9823, 2001
48. Yamamoto S, Yamamoto N, Kitamura T, et al: Proliferation of parenchymal neural progenitors in response to injury in the adult rat spinal cord. Exp Neurol 172:115-127, 2001

49. Zhang SC, Wernig M, Duncan ID, et al: In vitro differentiation of transplantable neural precursors from human embryonic stem cells. Nat Biotechnol 19:1129-1133, 2001

Manuscript received July 15, 2005.

Accepted in final form August 16, 2005.

Address reprint requests to: Nicholas C. Bambakidis, M.D., Neuroscience Publications, Barrow Neurological Institute, 350 West Thomas Road, Phoenix, Arizona 85013. email: neuropub@chw.edu. 